\title{
Urban Housing Policy Considerations: Perspectives from the Finnish Housing Market Marko Hannonen ${ }^{1}$
}

\begin{abstract}
It is very difficult to study phenomena in housing markets using conventional so-called neoclassical economics. The core problem stems from the highly unrealistic assumptions of neoclassical economics, such as homogeneous products, equilibrium markets, ceteris paribus clauses, deterministic and linear systems, rationality of economic agents, and the utility maximization principle. New Keynesian economics appears to be a more fruitful approach to housing markets since it presumes that products are differentiated, markets are in disequilibrium state and there exists imperfect competition in a marketplace. Furthermore, new Keynesian economics utilizes the concept of bounded rationality, which is a more realistic description of the actual behavior of economic agents than the theoretical notion of rationality in neoclassical economics.
\end{abstract}

Keywords: Housing policy, ethics, state intervention, Keynesian economics

JEL Classification: $H 23, P 10$ and $R 31$

1 PhD, Researcher, Kiinteistötutkimus M. Hannonen Inc. 


\section{Background Information about Finnish Housing}

Finnish houses are generally more confined than those of other Western countries, although the quality of housing is relatively high. The number of dwellings in Finland (2.8 million) now exceeds the number of households (2.5 million). The arithmetic average size of households is 2.1 persons. The country's housing stock is also very young; over 60 percent of housing buildings were constructed from 1970 onwards.

Seventy-five percent of Finnish apartments are managed by households consisting of only one or two persons. In Finland (like in other Nordic countries), there are a great number of single-person households. In the city of Helsinki, for example, over half of households are single-individual unities. The living area per person in Finland one of the lowest in the Western world: approximately $40 \mathrm{~m} 2$. One out of five individuals in Finland (over 1 million persons) still lives in crowded conditions.

The arithmetic average size of Finnish houses is $80 \mathrm{~m} 2$ : Single-family houses have the largest living area and apartments have the lowest. The construction volume of houses has fluctuated greatly over the past two decades and there are currently approximately 30,000 new houses built in the country annually. The shortage of new construction is most visible in the city of Helsinki and the Helsinki Metropolitan Area.

Two-thirds of Finnish households live in owner-occupied houses and one-third in rental apartments (other housing forms constitute only 1 percent of the total housing stock). Almost 60 percent of Finnish households would prefer to live in owner-occupied singlefamily houses; in reality, however, only 40 percent of house-holds live in such dwellings, which means there is a large difference between housing preferences and the real world. Housing satisfaction is highest among households in single-family houses and lowest among people living in apartments. Finnish households desire $30 \mathrm{~m} 2$ of additional living area, which is understandable since dwellings are small in Finland.

\section{Challenges of Finnish Housing Policy²}

The average house size in Finland is the lowest amongst the EU15 countries, and there is no foreseeable significant improvement in the horizon. Also, the living area per person in Finland is one of the lowest of all Western countries, but it is slowly growing mainly due to the diminishing household size. Housing preferences are actualised poorly in Finland; for example, only 40 percent of housing units live in single-family houses, which is considerably less than is generally desired. Housing satisfaction is particularly low in the city of Helsinki, where only 10 percent are pleased with their accommodation. This is understandable since dwellings are very expensive and living areas are typically minimal (the price-quality relation is undeniably poor in Helsinki). Ninety percent of

\footnotetext{
${ }^{2}$ This chapter is based on the study [Hannonen, 2010b]
} 
households wish to live in owner-occupied houses, whereas only two-thirds actually have an owner-occupied house at the moment.

The most crucial practical problem in Finland is the shortage of housing supply, specifically in the Helsinki Metropolitan Area. The lack of sufficient new housing construction is a chronic distortion in Helsinki area that has existed over 15 years. Housing markets are clearly in a state of disequilibrium, with serious excess demand and evident under-supply; that is, market failure is tangible and profound. House prices have grown 3.5-fold higher level in the Helsinki Metropolitan Area since the late 1990s. The core of this problem is insufficient land supply; there is certainly enough land reserved in the local zoning plans, but these areas are not being turned into active land supply due to land ownership structure (the private sector owns a remarkable portion of this land). It has been calculated that only 10 percent of the original land reserved in the zoning process has been turned into active land supply in the last 10 years.

House prices are currently more than twice as high in the Helsinki Metropolitan Area as in the rest of the country. The arithmetic average unit house price of dwellings and semidetached houses is currently 3500 Euros in the Helsinki Metropolitan Area.

Government housing subsidiaries have dropped significantly during the last two decades and are now 1.2 percent of GDP. The largest portions of government aid to housing is allocated to the general housing allowances (0.5 percent of GDP) and to partial housing mortgage interest rate deductions ( 0.5 percent of the GDP). Subsidiary to new housing production in only 0.2 percent of GDP at the moment. Also, the nontaxability of owner-occupied housing sales profit is a significant government subvention, although that has never been officially included in the subvention calculations.

The main problematics of government subsidiaries relate to the partial housing mortgage interest rate deductions, which ultimately benefit only the seller of a house due to the capitalisation of this form of subsidiary to house prices. Furthermore, it is not ethically justifiable to allocate government aid only to owner-occupied housing and favour this housing form over other housing types. The starting point should be taxational neutrality between different housing modes. Also, the nontaxability of owneroccupied housing sales profit places owner-occupied housing in a better position than, for example, rental housing. In summary, the size of rental housing markets has shrunk to a level that is suboptimal from the economic perspective; this is hardly surprising given the long tradition of favouritism for owner-occupied housing in Finland.

Land policy establishes the foundations for any successful housing policy. Land policy instruments can be divided into two categories: land acquisition and implementation tools of land policy. The basic forms of land acquisition are: purchase of raw land and the municipality's right of redemption for land. The standard land policy implementation tools are land use contracts, development compensation, area development procedures, construction requests, real estate tax and building land arrangements. There are also some taxational incentives that can be used as 
supplementary tools along with the traditional land policy instruments. And, of course, all actions relating to land disposal (such as selling/renting) should be put into a separate category.

The best way to ensure that a municipality has the necessary amount of building land is usually to acquire raw land at the right time at the right places. This sort of activity is typically referred to as an active and a systematic approach to the implementation of land policy. However, in the city of Helsinki, for example, there is virtually no available raw land. Land use contracts are a popular way of rationally implementing zoning plans in Finland. A wide range of different tools can be applied in a given situation to accomplish the desired goals, but political interests have often prevented the rational land policy approach; for example, redemption and other compulsive vehicles are avoided for political reasons, even though the procedure would be socially beneficial and morally justified.

In Finland, there has traditionally been a strong concern that social coherence has prevailed and been enhanced and that segregation is seen only in a negative sense. However, this situation has changed greatly over the last two decades, during which time the Finnish economy has started to apply the neoclassical economics approach known as monetarism. As a consequence, income and wealth differences have increased and over one million people currently live on or below the poverty line in Finland. This phenomenon is clearly discernible in those housing markets where submarkets are strongly polarised into to 'good' and 'bad' housing areas (for example, Eastern Helsinki has a high concentration of unemployed people and immigrants, with an associated negative social stigma, and Western Helsinki is an area of wealthy people with high social status). Social divergence or segregation is a fact in modern Finland, and there is a trend towards an ever-higher social deviation between households, since political motivation to intervene this on-going process is virtually non-existent.

A problematic characteristic of the Finnish housing market has been a strong volatility of house prices. In fact, Finland's house price dynamic was the highest amongst the EU15 countries in the 1980s and 1990s. This is a direct consequence of the fundamental structural change of the entire Finnish society, which started in the late 1980s; namely, the shift from a mixed economy to a free-market economy. High house price volatility is a highly problematic feature of the Finnish system because it makes it extremely difficult to predict the future of housing markets, which in turn complicates planning and decision making process in housing policy issues. Therefore, one of the key objectives of any housing policy should be to enhance those actions that stabilise housing markets. Finnish politicians recognised this fundamental idea of Keynesian economics and increased the level of new housing construction during the recession of the 1990s and later in the (still on-going) recession of the late 2000s. However, the results of these actions have been moderate since the scope of the interventions has been insufficient. Overall, house price dynamics in the 2000s have been much lower than in earlier decades and the greatest uncertainty and threat lies in the fact that 90 percent of the housing mortgages in Finland are linked to openly fluctuating market interest rates. 
Regionally, the Finnish housing market is in a position of imbalance. The Helsinki Metropolitan Area suffers from a profound shortage of houses and the peripheral regions outside the growth centres suffer from high vacancy rates of accommodation. The continuing urbanisation process has meant that the regional imbalance is only expected to deepen. Citizens and dwellings are both aging fast as the baby boom generation retires from working life and the housing stock built around the 1970s starts to require complete renovation. Homelessness has become a noticeable phenomenon in the big cities; over half of the country's homeless individuals are located in the Helsinki Metropolitan Area (and the majority of these in the city of Helsinki). However, a positive aspect is the reducing trend observable in the level of homeless people.

Housing costs are especially high in the Helsinki Metropolitan Area and are facing increasing pressure from environmental policies. Recent changes in energy legislation have significantly increased the price of electricity and led to an increase of total housing costs. New housing construction now has to be energy-efficient and a special licence is required from single-family houses to meet the new environmental standards. Needless to say, these are a major challenge for many households that are already struggling with high housing cost levels. The Finnish urban structure is highly dispersed, which increases the total amount of cars used for travelling and thus raises the level of greenhouse emissions. One fundamental goal is to tighten the scattered urban structure.

\section{Future and Change of Finnish Housing ${ }^{3}$}

Our world will become increasingly complex and hectic, in which quantities and qualities of products are accelerating quickly. Globalisation is affecting the everyday life of common people. Digitalisation is proceeding steadily and urbanisation continues to enlarge the populations of major cities. Lifestyles are increasingly divergent and individualist. New technology will be integrated everywhere, including housing. Many developments or trends are expected to be realised in Finland in the near future. One example is environmental policies, which directly affect the housing sector through new regulations that will increase housing costs. Some environmental policies are in direct conflict with housing preferences, such as the need to compress the deviated urban structure, which conflicts with the basic desire of households to live in singlefamily houses surrounded by nature.

Urbanisation is a significant trend in the Finnish housing market, and together with immigration, these are increasing the populations of major cities, especially in the Helsinki Metropolitan Area. Immigration has created pressure to produce more large dwellings in the growth centres as immigrant families tend to be large and have a relatively large number of children.

\footnotetext{
${ }^{3}$ This chapter is based on the study [Hannonen, 2011b]
} 
Perhaps the most significant factor affecting housing preferences in Finland is the number of people is retiring from active work life. The number of people aged 65 and over will almost double within the next two decades, which will certainly influence housing preferences.

In the housing policy framework, it is difficult to evaluate the future development of housing preferences since the decisions have to be analysed in the long term and influence many different areas of human life. Predictability is significantly reduced as the so-called normal trajectories in the Finnish society, culture and politics disappear. However, in many ways we do have a clear vision of what households typically desire. People want to life in single-family or semi-detached houses near nature in a peaceful area. Whether these desires are realistic or not is another issue.

Overall, it can be stated that the diversity of housing choices is increasing, housing products are becoming globalised and the amount of housing services needed in the local market will grow. There will be specific product and service operators in housing markets that will work in the boundary area of consumers and producers. This will challenge conventional urban planning; for example, in terms of zoning policies.

\section{Ethical Dimension of Housing Policy}

There are various theories regarding ethical issues. A popular one is the framework that emphasises the consequences of ethical choices. This view says that individuals should always act in a way that leads to the best possible outcome attainable, as this will lead to an increased amount of goodness. This section adapts the ethics of consequences as a context that applies to practical matters of housing economics and is consistent with the neoclassical economics principle of individual utility maximisation. The present paper is concerned mostly with what should be (normative approach) and not so much with what really is (positive approach).

If an individual has a realistic perception of the phenomena occurring in housing markets, he/she has a better chance of making ethically sound decisions.

\subsection{Popular Concepts of Ethics}

Socrates considered that knowledge is the highest virtue, since people make bad things out of ignorance. As individuals gain knowledge, they achieve a better position in terms of conducting ethically correct choices. Aristotle believed that virtue is the middle way of two extreme alternatives, and that virtue can only be obtained by learning and education; that is, virtue is not an inborn or a genetic feature of any human being. Kant presented two categorical imperatives: (1) One should act according to the principle that one also wishes to be a general moral law, and (2) one should always regard other individuals as unique persons, not just as instrument for accomplishing something. Kant argued that there are absolute or objective moral values. 
Nietzsche's viewpoint was the opposite of Kant's and considered that there are two kinds of morality: aristocratic morality and slave morality. Aristocratic morality arises out of a noble individual and can be characterised as a life-affirming attitude that tends to create new values. Slave morality, on the other hand, is associated with a weak individual and is a life-denying view that bases its value principles on Christianity. Nietzsche categorically denied Kant's two categorical principles, and was therefore an ethical nihilist who fundamentally objected to the idea of the existence of absolute moral values. According to Nietzsche's moral view, every individual must become a superhuman (Übermensch), give up the rotten core of Christianity and its lifedegenerating value basis and, ultimately, create his or her own new ethical standards. Hume introduced the concept known as Hume's guillotine, which says that moral judgements cannot be derived from scientific facts. If this is true, what should ethical propositions be based on, if facts cannot serve as a foundation of moral codes? It is clear that society cannot operate rationally without the existence of some binding moral laws. Hume is correct that there are no absolute or objective moral truths. Instead, we must acknowledge that ethical issues are ultimately a collection of subjective views and interpretations of the matter.

\subsection{Ethical Questions of Housing and Land Policy}

Many land policy issues are inherently and fundamentally subjective. However, it can be argued that it is possible to obtain objective value basis as a certain kind of average of many different subjective judgements. This kind of reasoning relies on the scientific principle known as the Law of Large Numbers.

Values of land policies are spatially dependent; that is, they depend on the specific practices of a certain culture. The value basis of any land policy is also time-dependent; that is, dynamic and evolving through the flux of time. In Finland, there is a special emphasis on individual freedom and the integrity of private ownership in all circumstances.

The best-known economic philosopher of land policy is Henry George, who in the 19th century argued that society should legislate a special land value tax that collects the unjustified value increase to the hands of a society [George, 1879]. Today, the fundamental aim of any housing policy is to provide affordable housing for every household. Land policy plays a central role in this objective and its potential failure could lead to the situation that Japan is currently facing, where land costs in some cases represent up to 90 percent of total housing expenditures.

\subsection{Basic Value Concepts of Housing and Land Policy}

In land and housing markets, the investors and valuers need many kinds of value concepts to support the decision making process. These fundamental economic value terms include market value, income value and cost value. The market value of a property 
is the most probable selling price, which encloses the transaction between a willing seller and a potential buyer. Market value is usually the foundation of property pricing or valuation and is based on the local market price evidence about the object property and the comparables with relevant attribute information.

In practice, the market value of any property is a linear transformation of the evidence, which means that all the relevant information (such as extreme points) remains in that transformation. If the statistical estimator is sufficient, or the applied model is exhaustive, the information content of the original evidence in the data set can be passed in its entirety to a price estimate. Under this scenario, market price equals market value, which is determined objectively from the original evidence.

Sometimes, relevant price information is not obtainable or the data set is not sufficiently representative for any reliable practical use, meaning that different value concepts have to be applied. Therefore, income and cost value concepts are sometimes used and these concepts involve significant subjective assessment. For example, the determination of income value of a property necessitates the appraisal of future expected net revenues of the object property and the discount factor (which should reflect the future uncertainty relating to potential net income) to be used in calculations. Determining a cost value of a property involves the subjective question of depreciation and how to adequately measure it. Therefore, one cannot speak of the objective property value when using the income or the cost value as opposed to the market value.

\subsection{Practical Moral Dilemmas in Property Markets}

The general redemption law in Finland stipulates that compulsory acquisition is justified when necessitated by the public interest. This compulsory legislation is based on the premise that it guarantees an efficient, systematic and implementable urban planning, which benefits a larger group of local households. However, the compulsory law is seldom used in practice, even though it is juridically and ethically justified. Why is this? The answer lies in the local power politics that tend to reject the general interest and public welfare. Conservative parties ideologically consider the integrity of private ownership to be so fundamental and holy that it will never be endangered in practice, no matter what the consequences of this persistent insistence are. Another reason is the ignorance of local decision makers who do not know, for example, the difference between land policy and lot policy and that land reservations in local zoning plans are fundamentally different from the actual land supply available to use for building houses. Overall, one could argue that the redemption law is now practically dead legislation in Finland and has no real influence on the land and housing policies.

The issue of homelessness raises naturally ethical concerns. Why it is socially acceptable that some people do not have decent shelter? This is clearly a crime against humanity but most politicians and the media are not interested in the issue. Only when homeless people die in the cold of winter is there discussion about their plight, although this does not usually lead to significant tangible improvements in the nature of this negative social 
phenomenon. It should be stressed that the monetary investments needed to eradicate homelessness are marginal so that the reluctance stems elsewhere, probably from sheer indifference among local politicians and civil servants.

There has been a long tradition in Finland of favouring owner-occupied housing over rental housing. The starting point should ethically be a neutral attitude between different forms of housing alternatives. In practice, this favouritism of owner-occupied housing has led to a major shrinkage of rental housing markets, which is an economically suboptimal situation that is a real obstacle; for example, to a local adjustment of the amount of the unemployed. Also, a striking peculiarity in the Finnish housing policy has been its extensive focus on the so-called standard family model (two adults and two children), which has caused a significant shortage of small apartments, for example in the growth centres such as the city of Helsinki. Currently, 75 percent of households in Finland consist of only one or two individuals, which means that the standard household model cannot serve as a general model for any rational housing policy.

\section{Nature of Housing Markets}

Housing markets are incomplete mechanisms; that is, they are allocatively, operationally and informatively inefficient. The analysis of phenomena under these markets is a challenging task and housing markets are embedded with a collection of problematic practical features, including the following.

\section{Products in Housing Markets Are Differentiated}

Probably the most difficult premise of neoclassical economics is the assumption that products (goods and services) are homogeneous. This assumption enables the conventional comparative-static analysis, in which the price of a product is determined uniquely by the intersecting demand and supply curves.

In reality, for example in the housing market, houses are very heterogeneous and there is not even a single market but a collection of different local submarkets; in other words, the housing market is segmented.

Therefore, we need a totally different framework to validly analyse heterogeneous products, such as dwellings. This formalism, which is called hedonic pricing theory [Lancaster, 1966; Rosen, 1974], has become the fundamental approach in dealing with differentiated goods in housing and land markets. Hedonic pricing theory enables us to explicitly take into account the differing features or qualities that houses are composed of and derive the homogenised average house price for each and every submarket. 


\section{Housing Markets are in a Continuous State of Disequilibrium}

Another fundamental restriction in neoclassical economics is the assumption that markets are believed to be in equilibrium. This equilibrium concept is not properly defined and there are basically two relevant definitions: steady-state equilibrium and a system's normal equilibrium.

Steady-state equilibrium refers to an ancient ideal object proposed by the philosopher Plato, which means a stable and everlasting situation that is beyond our sense experiences in the world of ideals. Therefore, steady state is a reality that is independent of time. Another equilibrium concept is normal equilibrium, which means a situation in which variables under investigation do not change with the flux of time (more specifically, change can happen but only in a deterministic and perfectly predictable manner). The equilibrium concept of neoclassical economic models usually refers to normal equilibrium.

\section{Ceteris Paribus Clause is Often Violated}

The ceteris paribus clause is essential to the derivation of neoclassical economic models, especially for the interpretation of the results. This means that explanatory variables are assumed to be independent. In real life, regressors are typically highly correlated with each other, resulting in a situation known as multicollinearity, which is a serious threat to conducting empirical research in econometrics that stems from the fact that all economic variables tend to move together in the same way because of business cycles [Smith, 2002; Hannonen, 2010a].

\section{Nonlinearity}

The behaviour of economic variables constituting a system is usually nonlinear in nature [Anglin \& Gencay, 1996; Gencay \& Yang, 1996; Pace, 1993 \& 1995; Wallace, 1996], which is in direct conflict with the standard assumption of a system's linearity in neoclassical economics. This linearity assumption stems from the linear nature of standard operators in differential and integral calculus.

\section{Stochasticity}

Economic processes are assumed to be deterministic; that is, exactly and systematically defined by mathematical relations. However, economic phenomena encountered in real life are usually stochastic and characterised by randomness. It is important to understand the specific nature of this uncertainty in order to be able to use a correct probability measure for inference. 


\section{Boundedly Rational Expectations}

Rationality assumption does not correspond to the behaviour of real economic agents, which means it is more suitable to base the analysis on the notion of bounded rationality, which is utilized in new Keynesian and institutional economics [Simon, 1957].

\section{The Utility Maximisation Principle Is an Idealisation}

Measuring utility, even approximately, is difficult at the individual level, let alone at the aggregate level. Therefore, the utility concept is not an operational notion and cannot be measured in reality [Copeland et al, 2005, p. 13-31].

A more concrete alternative or criterion is required for the evaluation of theory, a model or method that reflects the actual way in which economic agents make decisions under uncertainty. The analytic hierarchy process (AHP) is one alternative that is widely applied in actual decision making processes and is operational and seems to be valid in real-life contexts [Saaty, 1980].

AHP supports multi-criteria decision making, which is based on mathematics and can utilise both qualitative and quantitative information in a natural manner. AHP has many applications in situations where, for example, preferences need to be ranked and ordered in order to reach a coherent conclusion for a final decision. This feature could be very useful in housing policy considerations that rely heavily on housing preferences that are currently not systematically analysed using any scientific method.

The new Keynesian economics appears as a fruitful approach with which to explore the phenomena in housing markets because it presumes that products are differentiated, markets are in disequilibrium state (constantly evolving), and there is an imperfect competition in a market place. Furthermore, the new Keynesian economics utilises the concept of bounded rationality, which is a more realistic description of the actual behaviour of economic agents than the theoretical notion of rationality in neoclassical economics. Also, new institutional economics applies the bounded rationality concept and emphasises the dynamics of economic systems and learning of economic agents.

Some of the fundamental laws in statistical physics also appear applicable for studying phenomena in housing markets. One of the main tasks of modern physics is to combine the analysis at the micro level to that of the macro level. In particular, the fundamental question is how to link the world of random phenomena (micro level) to the world of deterministic systems (macro level). The analogue is perfect to one of the basic problems in housing markets and economics in general.

Three fundamental scientific principles underlying thermodynamics in physics appeal as interesting for studying phenomena in housing markets and in the wider context of general economics. These are [Reichi, 2009]: 


\section{First rule of thermodynamics or conservation of energy}

This rule states that energy cannot be destroyed (or created), it can only alter its form. From the housing market perspective, this means that we can never construct and estimate such a model that would not distort or simplify reality. Our knowledge of the phenomena in housing markets will always be incomplete.

\section{Second rule of thermodynamics or increase of entropy}

A closed system will move towards the maximum probability or state in which entropy (which measures the level of randomness or uncertainly inherit with the system) is increased and energy is decreased.

However, housing markets are open systems. It is possible that an open system will near equilibrium, but this necessitates a form of back-propagation. From a housing market perspective, back-propagation means government intervention; that is, actions that reduce cyclical volatility and enable markets to move towards an equilibrium state.

\section{Third rule of thermodynamics or zeropoint of entropy}

All human action will end at the zeropoint of entropy. It cannot ever be reached.

This implies that, in housing markets, there cannot be a situation where all randomness or uncertainty underlying processes will disappear; that is, a system's behaviour will never be reduced to a pure deterministic process. Therefore, zeropoint of entropy is never reached in housing markets.

Statistical mechanics is appealing from the viewpoint of modelling phenomena in the housing market. Specifically, the second rule of thermodynamics seems a very general and a fundamental principle that states that closed systems tend to move towards equilibrium position (never completely reaching it), in which the system has maximum entropy and minimal energy.

The fact that economic systems are open means that reaching any equilibrium state is difficult in practice. However, the system usually tends to maintain its balance and this is possible in principle through back-propagation. Open economic systems are extremely unstable and highly sensitive, even to minor distortions. Therefore, positive backpropagation merely increases the instability of the system. Instead, negative backpropagation enables the system to move towards an equilibrium state.

Back-propagation implies that the government should use intervention (in the housing market, for example) to stabilise the system and thus enable it to reach a state of equilibrium. This is the fundamental insight of the new Keynesian economics, which justifies the intervention of a state or a municipality to practice, for example, an active housing policy [Hein, 2011]. 


\section{Theoretical Justification of Government Intervention in Housing Markets}

\subsection{Control-Theoretic Motivation}

Figure 1: A Hierarchical structure of public sector's actions related to housing policies

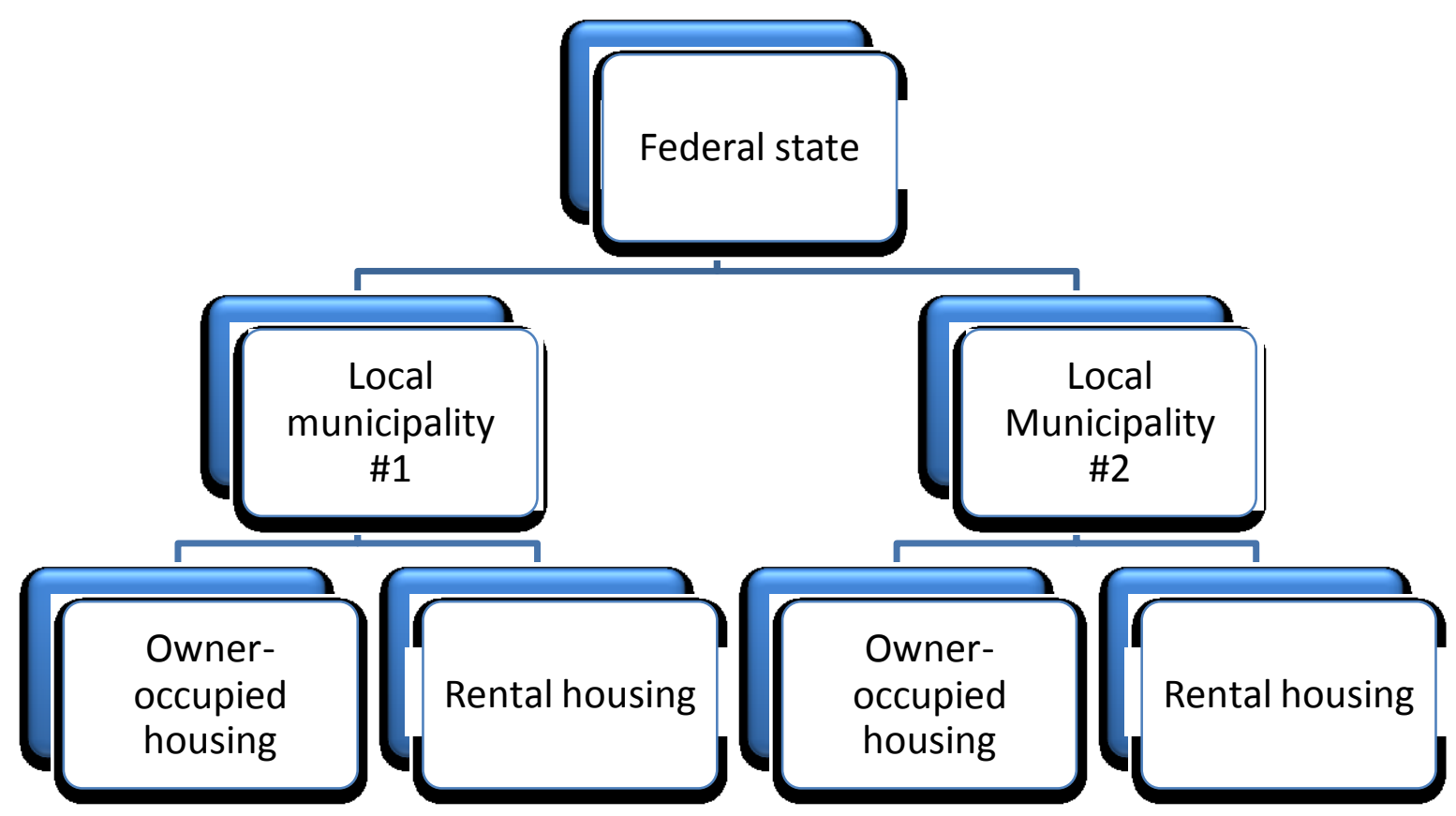

Source: Own elaboration.

Figure 1 depicts a basic hierarchical structure of public sector that makes decisions about housing policies. The state legislates the fundamental housing and land policy laws, and municipalities implement these laws when conducting their view of the relevant economic policy in local housing markets. In practice, municipalities have an independent role similar to pure autonomy to determine the mainlines of urban planning in their jurisdiction in Finnish society.

As stated above, back-propagation is an essential means with which to control any dynamic system; it can be positive in nature, forcing an external shock to a system, or negative in nature, weakening the influence of external distortion. A free-market economy is an ideal system that is inherently labile and highly sensitive to the smallest disturbances. Thus, a positive form of back-propagation only increases the instability of the system, whereas a negative form of back-propagation is a useful tool to enhance the system's tendency towards an equilibrium state. 
In general, back-propagation is not intended for long-term or continuous use but merely to stabilise temporary market distortions. Back propagation is always reactive; that is, it purports to fix the observable disorder but not the process itself. The most efficient form of back-propagation is typically positive dampening and negative enforcement.

Controllability and observability are essential elements when the impact of backpropagation is analysed to a system's performance. If the system is uncontrollable, then back-propagation is not the correct instrument with which to eliminate the market distortions and stabilise the process. In similar vein, if the system as a whole or some parts of it are unobservable, it is impossible to understand the genuine functioning of the market mechanism and the use of back-propagation will not lead to the necessary stabilisation of the process under investigation.

Figure 2 depicts a standard back-propagation scheme. The input describes the stimulus to the system and the output is the system's response to that stimulus. In Figure 2, A represents the dynamic model describing the behaviour of the system under study and $B$ represents the controller; that is, the intervention of the public sector.

Figure 2: Example of back-propagation

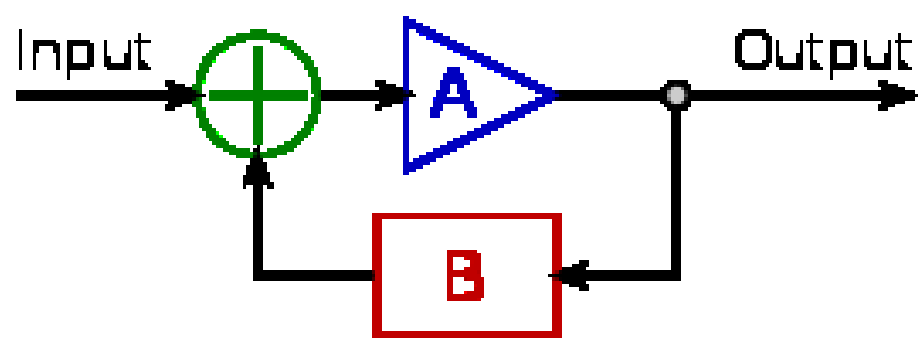

\subsection{Economic Motivation}

There is a strong economic motivation or incentive for government intervention in housing markets where market failure is occurring. Government intervention can be justified in terms of public interest. Government intervention may actualise when there is a Pareto suboptimal allocation of resources in the market place; that is free-market forces do not allocate scarce resources efficiently to produce the highest total social welfare.

Merit goods are products that the government feels that people will, if left to themselves, underconsume and should therefore be subsidised or provided free at the point of use. Houses are typical examples of merit (or mixed) goods so that the government intervention, in housing production for example, is natural, logical and socially justified. Both the public and the private sector of the economy can provide merit goods and services related to them. Consumption of merit goods is thought to generate positive externality effects where the social benefit from consumption exceeds the private benefit.

Market failure can also be caused by the existence of inequality throughout the economy. Significant differences in income and wealth between different groups within 
the economy leads to a wide gap in living standards between wealthy households and poorer people. Society may consider that too much inequality is unacceptable or undesirable and intervention is needed.

Oligopoly is a common market form in which a small number of firms are in competition. The oligopolists can significantly control the total production of houses and to produce less than would have been produced by a competitive industry. They reduce the number of housing units to be constructed and sold in the hope of higher prices (and thus, profits) for housing products. Housing markets usually only contain a couple of suppliers of housing goods and services and a multitude of potential buyers.

There is a case of imperfect or asymmetric information in housing markets and sellers usually have more information about the state and characteristics of the property than buyers. This information gap leads to high transaction costs that violate the basic principles of efficient market hypothesis. The lack or shortage of relevant market information leads to increased uncertainty about housing decisions and causes irrationality and instability in the market.

However, the fundamental objection to a perfect market mechanism is the fact that houses are differentiated products or, in particular, multidimensionally heterogeneous goods in terms of locational, structural and neighbourhood characteristics. This violates the very essence of efficient market formalism.

\section{Summary and Conclusions}

It is notoriously difficult to apply conventional or mainstream economics (so-called neoclassical economics) to the study of phenomena in housing markets. The core problematics of this orthodox economics stems from its highly unrealistic assumptions, such as homogeneous products, equilibrium markets, ceteris paribus clauses, deterministic and linear systems, rationality of economic agents, and the utility maximisation principle. The new Keynesian economics appears to be a more fruitful approach to housing markets since it presumes that products are differentiated, markets are in a state of disequilibrium and there is imperfect competition in a marketplace. Furthermore, the new Keynesian economics utilises the concept of bounded rationality, which is a more realistic description of the actual behaviour of economic agents than the theoretical notion of rationality in the neoclassical economics. 


\section{References}

Anglin, P.M. and Gencay, R. (1996). "Semiparametric Estimation of a Hedonic Price Function", Journal of Applied Econometrics, Vol. 11, 633-648.

Copeland, T.E., Weston, J.F. and Shastri, K. (2005), Financial Theory and Corporate Policy, 4th edition, Addison Wesley.

Gencay, R. and Yang, X. (1996). "A Forecast Comparison of Residential Housing Prices by

Parametric versus Semiparametric Conditional Mean Estimators", Economic Letters, Vol. 52, 129-135.

George, H. (1879). Progress and Poverty. 1912 ed. Garden City, N.Y.: Doubleday, Page.

Hannonen, M. (2005a). "On the Recursive Estimation of Hedonic Prices of Land", Nordic Journal of Surveying and Real Estate Research, Vol. 2, No. 2, 30-56.

Hannonen, M. (2005b). "An Analysis of Land Prices: A Structural Time-Series Approach", International Journal of Strategic Property Management, Vol. 9, No. 3, 145-172.

Hannonen, M. (2010a). "The Determinants of House Prices" (in Finnish), Research Report, 1.1.2010, Kiinteistötutkimus M. Hannonen.

Hannonen, M. (2010b). "On the Evaluation of the Finnish Housing Policy” (in Finnish), Research Report, 1.6.2010, Kiinteistötutkimus M. Hannonen.

Hannonen, M. (2011a). "On the Determination of Apartment Rents in Some Major Cities of Finland” (in Finnish), Research Report, 1.1.2011, Kiinteistötutkimus M. Hannonen.

Hannonen, M. (2011b). "The Future and Change of the Finnish Housing" (in Finnish), Research Report, 1.6. 2011, Kiinteistötutkimus M. Hannonen.

Hein, E. (2011). A Modern Guide to Keynesian Macroeconomics and Economic Policies, Berlin School of Economics and Law, Germany and Engelbert Stockhammer, Kingston University, UK.

Laakso, S. \& Kostiainen, E. (2009). "The Current State and the Future Prospects of Hybrid Forms of Housing in the Helsinki Metropolitan Area", Economic and Planning Center, Publication 2/2009.

Lancaster, K. J. (1966). A new approach to consumer theory, Journal of Political Economy, Vol. 74, 132-157.

Pace, K. (1993). “Nonparametric Methods with Applications to Hedonic Models”, Journal of Real Estate Finance and Economics, Vol. 7, 195-204.

Pace, K. (1995). "Parametric, Semiparametric, and Nonparametric Estimation of Characteristic Values Within Mass Assessment and Hedonic Pricing Models", Journal of Real Estate Finance and Economics, Vol. 11, 195-217.

Reichi, L.E. (2009). A Modern Course in Statistical Physics, Wiley-WCH.

Rosen, S. (1974). "Hedonic Price and Implicit Markets: Product Differentiation in Pure Competition", Journal of Political Economy, Vol. 82, No. 1, 34--55.

Saaty, T.L. (1980). The Analytic Hierarchy Process: Planning, Priority Setting, Resource Allocation, McGraw-Hill. 
Simon, H. (1957). A Behavioral Model of Rational Choice, in Models of Man, Social and Rational: Mathematical Essays on Rational Human Behavior in a Social Setting. New York: Wiley.

Smith, S. (2002). Violated laws, ceteris paribus clauses, and capacities, Synthese, Vol. 130, No. 2, Feb. 2002, 235-264.

Vasanen, A. (2010). "Flashes of Light in the Darkness of Housing Precefences" (in Finnish), Yhdyskuntasuunnittelu, Vol. 48, No. 3, 26-34.

Virtanen, P. V. (2004). "A Crying Voice in a Certain Country" (in Finnish), Maankäyttö $1 / 2004$. 